University of Texas at El Paso

ScholarWorks@UTEP

$11-2016$

\title{
It Is Advantageous to Make a Syllabus As Precise As Possible: Decision-Theoretic Analysis
}

\author{
Francisco Zapata \\ The University of Texas at El Paso, fazg74@gmail.com \\ Olga Kosheleva \\ The University of Texas at El Paso, olgak@utep.edu \\ Vladik Kreinovich \\ The University of Texas at El Paso, vladik@utep.edu
}

Follow this and additional works at: https://scholarworks.utep.edu/cs_techrep

Part of the Computer Sciences Commons

Comments:

Technical Report: UTEP-CS-16-82

\section{Recommended Citation}

Zapata, Francisco; Kosheleva, Olga; and Kreinovich, Vladik, "It Is Advantageous to Make a Syllabus As Precise As Possible: Decision-Theoretic Analysis" (2016). Departmental Technical Reports (CS). 1051. https://scholarworks.utep.edu/cs_techrep/1051 


\title{
It Is Advantageous to Make a Syllabus As Precise As Possible: Decision-Theoretic Analysis
}

\author{
Francisco Zapata ${ }^{1}$, Olga Kosheleva ${ }^{2}$, and \\ Vladik Kreinovich ${ }^{1}$ \\ ${ }^{1}$ Department of Computer Science \\ ${ }^{2}$ Department of Teacher Education \\ University of Texas at El Paso \\ $500 \mathrm{~W}$. University \\ El Paso, TX 79968, USA \\ fazg74@gmail.com, olgak@utep.edu, \\ vladik@utep.edu
}

\begin{abstract}
Should a syllabus be precise? Shall we indicate exactly how many points we should assign for each test and for each assignment? On the one hand, many students like such certainty. On the other hand, instructors would like to have some flexibility: if an assignment turns out to be more complex than expected, we should be able to increase the number of points for this assignment, and, vice versa, it it turns out to be simpler than expected, we should be able to decrease the number of points.

In this paper, we analyze this problem from a decision-theoretic viewpoint. Our conclusion is that while a little flexibility is OK, in general, it is beneficial to make a syllabus as precise as possible.
\end{abstract}

\section{Should a Syllabus Be Precise?}

Formulation of the problem. Shall we indicate exactly how many points we should assign for each test and for each assignment? On the one hand, many students like such certainty. On the other hand, instructors would like to have some flexibility:

- If an assignment turns out to be more complex than expected, we should be able to increase its weight.

- Vice versa, it it turns out to be simpler than expected, we should be able to decrease the number of points.

What we do in this paper. In this paper, we analyze this problem from a decision-theoretic viewpoint. Our conclusion is that while a little flexibility is 
OK, in general, it is beneficial to make a syllabus precise.

\section{Decision Making: A Brief Reminder}

Decision making: general case. According to decision theory (see, e.g., $[1,4,5,6,7])$ decisions of a rational agent can be equivalently described as maximizing an appropriate objective function $u(a)$. This objective function is known as the utility function.

Decision making under uncertainty. In some cases, we do not know the exact consequences of each possible action. In this case, for each action $a$, instead of the exact value $u(a)$ of the corresponding utility, we only know the interval of possible values: $[\underline{u}(a), \bar{u}(a)]$.

In such situations, a rational agent should select an action $a$ that maximizes the expression

$$
u(a) \stackrel{\text { def }}{=} \alpha \cdot \bar{u}(a)+(1-\alpha) \cdot \underline{u}(a) .
$$

This optimism-pessimism criterion was first formulated by a Nobelist Leo Hurwicz $[2,3,5,6]$ :

- The optimism value $\alpha=1$ means that a person only takes into account best-case consequences.

- The pessimism value $\alpha=0$ means that a person only takes into account worst-case consequences.

- A realistic approach is to take $\alpha \in(0,1)$.

In particular, there are reasonable arguments in favor of selecting $\alpha=0.5$.

\section{Analysis of the Situation}

In general, the overall grade $g$ for the class is a weighted average of grades $g_{i}$ on different assignments:

$$
g=w_{1} \cdot g_{1}+\ldots+w_{n} \cdot g_{n}, \text { with } \sum_{i=1}^{n} w_{i}=1 .
$$

The grade $g_{i}$ on each assignment depends on the student's efforts $g_{i}=f\left(e_{i}\right)$. Let us assume that a student has a certain overall amount of effort $E$ dedicated to this class; then:

- among all possible combinations $e_{i}$ with $\sum_{i=1} e_{i}=E$,

- the student selects the one that maximizes his/her utility. 


\section{Case of a Precise Syllabus}

In a precise syllabus, the weights $w_{i}$ are explicitly stated. In this case, the student maximizes $\sum_{i=1}^{n} w_{i} \cdot f\left(e_{i}\right)$.

For equal weights, Lagrange multiplier approach leads to

$$
\sum_{i=1}^{n} w_{i} \cdot f\left(e_{i}\right)+\lambda \cdot\left(\sum_{i=1}^{n} e_{i}-E\right) \rightarrow \min .
$$

Differentiating with respect to $e_{i}$ and equating derivative to 0 , we get

$$
w_{i} \cdot f^{\prime}\left(e_{i}\right)=-\lambda \text {. }
$$

In particular, when assignments are of equal complexity and $w_{i}=$ const, we get $e_{i}=$ const. Thus, a precise syllabus encourages students to learn all the topics.

This is exactly what we instructors want.

\section{Case of an Imprecise Syllabus}

Imprecise syllabus: general case. Let us now consider the extreme case of an imprecise syllabus, when no information is provided about $w_{i}$. In this case, the best-case gain is

$$
\bar{u}=\max _{i} g_{i}=\max _{i} f\left(e_{i}\right) .
$$

This gain corresponds to the case when:

- the assignment with the highest grade gets weight 1 , and

- other assignments get weight 0 .

The worst-case gain is $\underline{u}=\min _{i} g_{i}=\min _{i} f\left(e_{i}\right)$. This gain corresponds to the case when:

- the assignment with the lowest grade gets weight 1 , and

- other assignments get weight 0 .

Thus, a student maximizes the expression

$$
u=\alpha \cdot \max _{i} f\left(e_{i}\right)+(1-\alpha) \cdot \min _{i} f\left(e_{i}\right)
$$

What if a student diligently studies. If a student diligently studies each topic, we have

$$
e_{i}=\frac{E}{n}, \text { and } u=f\left(\frac{E}{n}\right)
$$


What if a student gambles. On the other hand, if the student gambles and places all his/her efforts into one topic, then

$$
\max _{i} g_{i}=f(E) \text { and } \min _{i} g_{i}=0 .
$$

In this case, $u=\alpha \cdot f(E)$.

So what will a student do? So, if $\alpha \cdot f(E)>f\left(\frac{E}{n}\right)$, the student will gamble instead of studying each topic.

No matter what $\alpha>0$ is, for sufficient large $n$, we have

$$
f\left(\frac{E}{n}\right) \rightarrow f(0)=0 .
$$

Thus, for large $n$, the above inequality will be satisfied. So, an imprecise syllabus encourages gambling approach instead of a diligent thorough study.

\section{Conclusion: It Is Advantageous To Make Syl- labi Precise}

A precise syllabus encourages a student to study all the topics - this is what we instructors would like to see. On the other hand, an imprecise syllabus encourages gambling approach instead of a diligent thorough study.

Thus, it is advantageous to make a syllabus as precise as possible.

\section{Acknowledgments}

This work was supported in part by the National Science Foundation grants HRD-0734825 and HRD-1242122 (Cyber-ShARE Center of Excellence) and DUE-0926721, and by an award from Prudential Foundation.

The authors are thankful to all the participants of the 19th UTEP/NMSU Workshop on Mathematics, Computer Science, and Computational Science (El Paso, Texas, November 5, 2016) for valuable discussions.

\section{References}

[1] P. C. Fishburn, Utility Theory for Decision Making, John Wiley \& Sons Inc., New York, 1969.

[2] L. Hurwicz, Optimality Criteria for Decision Making under Ignorance, Cowles Commission Discussion Paper, Statistics, No. 370, 1951. 
[3] V. Kreinovich, "Decision making under interval uncertainty (and beyond)", In: P. Guo and W. Pedrycz (eds.), Human-Centric Decision-Making Models for Social Sciences, Springer Verlag, 2014, pp. 163-193.

[4] D. Luce, Inividual Choice Behavior: A Theoretical Analysis, Dover, New York, 2005.

[5] R. D. Luce and H. Raiffa, Games and Decisions: Introduction and Critical Survey, New York, Dover, 1989.

[6] H. T. Nguyen, O. Kosheleva, and V. Kreinovich, "Decision making beyond Arrow's 'impossibility theorem', with the analysis of effects of collusion and mutual attraction", International Journal of Intelligent Systems, 2009, Vol. 24, No. 1, pp. 27-47.

[7] H. Raiffa, Decision Analysis, Addison-Wesley, Reading, Massachusetts, 1970. 